\title{
Conscious Sedation in Dentistry - A Review of Commonly Used Drugs
}

\section{Nasser F Al Qahtani ${ }^{1}$, Ahad F Al Qahtani ${ }^{2}$, Modi F Al Qahtani ${ }^{3}$, Majedah F Al Qahtani ${ }^{4}$ and Ganesh Rajendran ${ }^{5 *}$}

${ }^{1}$ Clinical Pharmacologist, Orange Pharmacy, Riyadh, Kingdom of Saudi Arabia

${ }^{2}$ Undergraduate Student, Dentistry Program, Ibn Sina National College of Medical

Studies, Jeddah, Kingdom of Saudi Arabia

${ }^{3}$ Undergraduate Student, Medicine Program, Faculty of Medicine, Al Baha

University, Al Baha, Kingdom of Saudi Arabia

${ }^{4}$ Undergraduate Student, Medicine Program, Ibn Sina National College of Medical

Studies, Jeddah, Kingdom of Saudi Arabia

${ }^{5}$ Assistant Professor of Pediatric Dentistry, Department of Preventive Dental

sciences, Faculty of Dentistry, Al Baha University, Al Baha, Kingdom of Saudi Arabia

*Corresponding Author: Ganesh Rajendran, Assistant Professor of Pediatric

Dentistry, Department of Preventive Dental sciences, Faculty of Dentistry, Al Baha

University, Al Baha, Kingdom of Saudi Arabia.

DOI: 10.31080/ASDS.2021.05.1091
Received: March 15, 2021

Published: April 06, 2021

(C) All rights are reserved by Ganesh

Rajendran., et al.

\section{Abstract}

The main concern of the dentist and the preference of the patients are to have minimal pain or painless dentistry. Both children and adult's express anxiety, pain and distress during the dental treatment, hence its natural to dentist to follow the methods to relieve the above. The conscious sedation provides more comfort and helps in more comfortable and less painful dental procedures. Here we have discussed the various drugs used to achieve conscious sedation in dentistry.

Keywords: Conscious Sedation; Dentistry; Drugs

\section{Introduction}

One of the main objectives of dentist is to provide pain control and minimal pain during dental procedures [1]. Various pharmacological methods have been used to attain the require amount of conscious sedation in the dentistry. This also depends upon the patients response to the different types of sedative drugs [1]. The conscious sedation is defined as "A technique in which the use of a drug or drugs produces a state of depression of the central nervous system enabling treatment to be carried out, but during which verbal contact with the patient is maintained throughout the period of sedation. The drugs and techniques used to provide conscious sedation for dental treatment should carry a margin of safety wide enough to render loss of consciousness unlikely" [2]. Later the definition was updated and defined as "Conscious sedation is a drug-induced depression of consciousness during which the patient responds purposefully to verbal commands, either alone or accompanied by light tactile stimulation. No interventions are required to maintain a patent airway, and spontaneous ventilation is adequate and vital functions maintained" [3]. 
The difficulties which may be faced during conscious sedation are shared airway between the dentist and the anesthesiologist, phobia and anxiety, preexisting cardiac anomalies, mental instability, and epilepsy. Enlarged tonsils and adenoids in children likely to precipitate respiratory obstruction, risk of patient losing consciousness, respiratory, and cardiovascular depression, vasovagal syncope due to the dependent position of legs in dental chair $[4,5]$. Hence to beat all this the anesthetist should be prepared before starting the procedure. A detailed medical record should be recorded by the dentist to rule out the preexisting conditions.

The common indications for conscious sedation are patients who express dental phobia, anxiety traumatic and long dental procedures, medical conditions aggravated by stress such as angina, asthma and epilepsy, children above 1 year of age, mentally challenged individuals.

The review of common drugs used in conscious sedation are below:

- Nitrous oxide: It had been one among the primary modern anesthetics, was first manufactured in 1772 by English chemist, Joseph Priestly. Sir Humphrey Davy in 1800 experimented with the physiological properties of the nitrous oxide gas and explained that: "As inhalation general anesthetic in its extensive operation appears capable of destroying physical pain, it may probably be used with advantage during surgical operation" [6]. It is a mildly sweet-smelling and colorless gas that is non-irritant to tissues, with a minimal alveolar concentrations and it is used along with oxygen as sedation [7]. The inhalation anesthetic has anxiolytic effect which is got by agonism at benzodiazepine binding sites on the GABAA receptor and a potentiation of a signaling pathway that involves this $\mathrm{N}_{2} \mathrm{O}$ synthase, soluble guanylyl cyclase and cGMP-dependent protein kinase. The other important one is the analgesic effects of nitrous oxide which occurs by the discharge of endogenous opioid peptides within the central nervous system and subsequent inhibition of pain pathways via opioid receptors [7]. This has property of low tissue solubility it enables rapid onset of action in addition to a rapid recovery; thus ensuring a controlled sedation and quick return to normal activities. Hence it is safer because the patient is responsive and stays awake throughout the procedures [8].
- Ketamine: It is a N-methyl-D-aspartate receptor (DMDAR) agonist. Ketamine is more preferred due to its lower effect on the circulation and also in the respiration compared to others. It provides dissociate type of anesthesia, which could be a unique state. Here the patient will show lack of pain but the cardiovascular and respiratory functions are well preserved [8]. It also results in analgesia and amnesia. The utilization of ketamine can provide safe, effective, and timely sedation in pediatric patients irrespective of the route of administration [9]. Green., et al. has explained about ketamine and described the dose of $3-4 \mathrm{mg} / \mathrm{kg}$ for intramuscular or intravenously at a dose of $1-2 \mathrm{mg} / \mathrm{kg}$ [10].

- Benzodiazepines: The diazepam and midazolam are the common benzodiazepines used in dentistry. They're one among the safe drugs for intravenous conscious sedation. These drugs are popular in dentistry because of their wide margin of safety. They also provide muscle relaxation and anticonvulsant activity. It acts by GABA-mediated opening of chloride channels. It's added to nitrous oxide to obtain the desired effects. Its highly lipophilic hence they cause rapid onset of action [11]. The standard administration of diazepam is 5 or $10 \mathrm{mg}$ orally, 1 hour before the procedure and, for more severe cases of anxiety, 5 or $10 \mathrm{mg}$ administered orally the night before the procedure and another 5 or 10 mg administered orally 1 hour before the procedure. As midazolam doses may be around 7.5 to 15 , or 0.3 to $0.5 \mathrm{mg} / \mathrm{kg}$ of body weight in pediatric patients, are administered $30 \mathrm{~min}$ utes before procedures [12].

- Sevoflurane: This is a powerful anesthetic agent; hence its employed in pediatric dentistry whenever deep sedation is required [13]. This is often utilized in inhalational form with rapid onset and recovery rate [14]. The usage of this provides a safe and pleasant technique whenever deeper sedation is needed in dental procedures [14].

- Propofol: This is an example of short acting intravenous sedative. It is made up of 2,6-diisopropylphenol. Propofol is reported to act via gammaaminobutyric acid (GABA)A receptors where the hypnotic actions are activated by central inhibitory neurotransmitter GABA [15]. It can be used as its one of the safe method of sedation. It is also highly lipophilic so its rapid acting to. The dosage given is between $1-1.5 \mathrm{mg} /$ $\mathrm{kg}$ of body weight and followed by maintenance dose rang- 
ing from 0.3 to $4 \mathrm{mg} / \mathrm{kg} /$ body weight $[8,16]$. Care should be taken when using it for sedation, as they show significant risks for cardiac and respiratory complications, making it crucial that the administration of this drug be provided by a practitioner who is well trained in general anesthesia [17].

- Opioids: As most of sedative drugs don't provide analgesia we need to use opioids to get the required analgesic effect. They provide profound analgesic effect when used. Side effects with opioid drug are nausea, vomiting, risk of hypotension, respiratory depression, drug dependence and withdrawal symptoms [18]. The common drugs used nowadays are fentanyl, sufentanil. Fentanyl is more potent than morphine and has rapid onset of action, hence can be used. It can be administered by parenteral, transdermal, nasal, and oral routes. The dose given is $1 \mathrm{mcg} / \mathrm{kg} / \mathrm{dose}$ IV [5]. The synthetic type of drug is sufentanil and its highly potent, 5 - 10 times more effective than fentanyl. Sufentanil is fat soluble, crosses membranes easily and also show rapid recovery. When used in children the common side effects are reduced chest wall compliance, nausea, vomiting and a prolonged discharge time in comparison to nasally administered midazolam $[19,20]$.

\section{Conclusion}

Both children and adults who express fear anxiety or dental phobia can be treated better with conscious sedation. It is important to understand the pharmacology of the drugs and its effects prior to using it. For patients who require sedation, proper medical history and preanesthetic assessment should be done prior to the procedures. The dental personnel should be trained well before performing the conscious sedation. So finally we will be able to minimize anxiety and minimize discomfort during dental treatment.

\section{Bibliography}

1. Council O. "Guideline on use of nitrous oxide for pediatric dental patients". The Pediatric Dental Journal 38.6 (2016): 211215.

2. Sheroan MM., et al. "A prospective study of 2 sedation regimens in children: chloral hydrate, meperidine, and hydroxyzine versus midazolam, meperidine, and hydroxyzine". Anesthesia Progress 53.3 (2006): 83-90.
3. Galeotti A., et al. "Inhalation Conscious Sedation with Nitrous Oxide and Oxygen as Alternative to General Anesthesia in Precooperative, Fearful, and Disabled Pediatric Dental Patients: A Large Survey on 688 Working Sessions". BioMed Research International (2016): 7289310.

4. Harbuz D and O'Halloran M. “Techniques to administer oral, inhalational, and IV sedation in dentistry". Australasian Medical Journal 9.2 (2016): 25-32.

5. Attri J., et al. "Conscious sedation: Emerging trends in pediatric dentistry". Anesthesia, Essays and Researches 11.2 (2017): 277.

6. Academy T., et al. "Nitrous Oxide Sedation: A Basic Review" (2020).

7. Emmanouil DE and Quock RM. "Advances in understanding the actions of nitrous oxide". Anesthesia Progress 54.1 (2007): 9-18.

8. Kapur A and Kapur V. "Conscious sedation in dentistry". Annals of Maxillofacial Surgery 8.2 (2018): 320-323.

9. Oh S and Kingsley K. "Efficacy of Ketamine in Pediatric Sedation Dentistry: A Systematic Review". Compendium of Continuing Education in Dentistry 39.5 (2018): e1-e4.

10. Green SM., et al. "What is the optimal dose of intramuscular ketamine for pediatric sedation?" Academic Emergency Medicine (1999): 621626.

11. Finder RL MP. “Benzodiazepines for intravenous conscious sedation". Agon Antagon Compend 14 (1993): 972.

12. Cogo K., et al. "Conscious sedation with benzodiazepines in dentistry". Revista de Odontologia da Universidade Cidade 18 (2006): 181-188.

13. Kim SO., et al. "Deep sedation with sevoflurane inhalation via a nasal hood for brief dental procedures in pediatric patients". Emergency Care 29.8 (2013): 926-928.

14. Ganzberg S., et al. "Use of sevoflurane inhalation sedation for outpatient third molar surgery". Anesthesia Progress 46.1 (1999): 21-29.

15. Asahi Y., et al. "Dose requirements for propofol anaesthesia for dental treatment for autistic patients compared with intellectually impaired patients 37.1 (2009): 70-73. 
16. Rai K and Hegde AM GK. "Sedation in uncooperative children undergoing dental procedures: a comparative evaluation of midazolam, propofol and ketamine". The Journal of Clinical Pediatric Dentistry 32.1 (2007): 1-4.

17. Saraghi M., et al. "Propofol: an overview of its risks and benefits". Compendium of Continuing Education in Dentistry 34.4 (2013): 252-258.

18. Titsas A and Ferguson MM. "Impact of opioid use on dentistry". The Australian Dental Journal 47.2 (2002): 94-98.

19. Monk JP and Beresford R WAS. "A review of its pharmacological properties and therapeutic use". Drugs 36.3 (1988): 286-313.

20. Binstock W., et al. "The effect of premedication with OTFC, with or without ondansetron, on postoperative agitation, and nausea and vomiting in pediatric ambulatory patients". Paediatric Anaesthesia 14 (2004): 759-767.

\section{Assets from publication with us}

- Prompt Acknowledgement after receiving the article

- Thorough Double blinded peer review

- Rapid Publication

- Issue of Publication Certificate

- High visibility of your Published work

Website: www.actascientific.com/

Submit Article: www.actascientific.com/submission.php

Email us: editor@actascientific.com

Contact us: +919182824667

Citation: Ganesh Rajendran., et al. "Conscious Sedation in Dentistry - A Review of Commonly Used Drugs". Acta Scientific Dental Sciences 5.5 (2021): 10-13. 